\title{
The Basic Training of Pavlo Hummel and \\ Static Pop Culture Ideas on Male Gender
}

\author{
Zane Scott-Tunkin
}

Pavlo Hummel in David Rabe's (1940-) play The Basic Training of Pavlo Hummel $^{1}$ thinks he knows why he is in the army. He has enlisted during the Vietnam War rather than be drafted, so his uniform states "Regular Army." Yet he is subjected to the teasing and taunting of the rest of those in boot camp. Pavlo simply cannot understand it. He has done everything to fulfill what he sees as the role of an American male. He thinks he has done so by fulfilling the sacred act of duty to his country, but to embody his ideal, Hummel tells tall tales, romanticizes violence, and takes his cues from idolized, pop-culture "steel" men. Emulating his idols, Hummel searches through basic training for a chance to embody the unattainable ideal that his examples have set forth. In the end, Pavlo falls short, terribly short, getting himself killed due to his desire to fill the shoes of what he sees as the true American male ${ }^{2}$. The experiences of the title character act as a showcase of the failings of static male gender roles and their rigidity during the Vietnam conflict.

Basic Training, one of Rabe's four works commonly referred to as the "Vietnam Plays," is part of the overall American theatrical response to the United States' involvement in the Vietnam conflict. When quickly scanning the reply of the domestic art community to war in Vietnam, the casual observer will see only two camps, viewing the war either positively or negatively. But the tendency to confine such a complex engagement into extremely narrow binaries is a mistake and a disservice to the men and women who served in the armed forces during this time. Their voices were often lost amidst the vocal debate over policy and direction on the home front. According to Michael Herr, author of the book Dispatches, "We all had roughly the same position on the war: we were in it, and that was a position." Herr's words demonstrate Rabe's principal framing of Vietnam throughout the text of his "Vietnam Plays." Prior to the appearance of Rabe and similar playwrights, the theatrical response to Vietnam was either concerned with ending it, or merely escaping it for a couple of hours. Many previous efforts to address Vietnam failed to examine the experience of the individual soldier as he moved within the military; instead, early attempts were made at turning each audience against the conflict as a whole, as a matter between nations.

Vietnam reverberated in the American dramatic community in four evolutionary and dramatic shifts that took place during the 1960s, as detailed by Jeffery Fenn. Fenn divides the various segments of counter-culture theatre into four types: the experimental theatre, the radical theatre, the documentary theatre, 


\section{Zane Scott-Tunkin}

and theatre of abstraction. ${ }^{4}$ Each is associated with one particular troupe or personality. The experimental theatre, characterized by a breakdown of traditional actor-audience relationships and the belligerent handling of socially and culturally divisive subject matter, was exemplified in Judith Malina and Julian Beck's "living theatre," which they launched out of their New York City apartment in 1951..$^{5}$ The living theatre distinguished itself by throwing away the conventions regarding an actor's relationship with the audience and what is considered the "fourth wall," or the imaginary wall between the performers on stage and the audience beneath.

While experimental theatre toyed with the medium of traditional theatre (an audience observes the action and progression on stage, with minimal to no interaction with the audience), in order to tweak its message, radical theatre came close to throwing out medium for sake of message. Realizing that the typical theatre audience was wealthy enough to afford the ticket and generally conservative, those grouped into the radical theatre, such as the San Francisco Mime Troupe (1959) took their message directly to the streets and therefore straight to their audience, using practices common to "guerilla theatre." The radical theatre took on many incarnations, including mime troupes, puppet shows, dances, "militant" theatre, and outdoor protest as theatrical expression. ${ }^{7}$

In wanting to bring the rawness of the events concurrently happening in Vietnam to the stage and their audience, a group of performers and writers adapted things such as news reports, magazine articles, and documentary film into their performances, which were based upon actual events. ${ }^{8}$ By interweaving "hard news" into their performances, documentary theatre sought to bring a certain degree of credibility to theatre as a protest movement and medium. Such realism was remarkably absent from traditional theatre during the Vietnam conflict. ${ }^{9}$ Mainstream American theatre served as an escape for a public inundated with news reports, including pictures and video that constantly reminded them of the war.

Theatres that were chiefly concerned about their economic stability did not wish to touch upon Vietnam out of fear of alienating their source of revenue. Vietnam was not acceptable subject matter. Theatres or performing groups that addressed Vietnam directly prior to the discussion concerning American withdrawal were regarded as fringe groups that viewed theatre not as an escapist medium but instead as a powerful, confrontational catalyst for change in policy. As Robert Asahina points out in Levitating the Pentagon, "Vietnam was not even raised in American theatres until 1971, some six years after the escalation of conflict, three years after the peak of American involvement, and well after public opinion had turned against the war."10 It was not until 1971 that commercially viable operations viewed Vietnam overall as well as critical pieces on the subject as acceptable material for the playbill. Asahina refers to the popular, mainstream American theatre, what Fenn refers to as "theatre of abstraction." On those stages, Vietnam did not exist, as the war and the debate about it raged just outside the auditorium's doors.

David Rabe is part of the delayed response to Vietnam of the larger theatrical 


\section{The Basic Training of Pavlo Hummel}

community or what Asahina terms the "American theatre." Rabe grew up in the heart of America. An Iowa native, he attended Loras College and pursued his graduate studies at Villanova University following his return from his service as a medic in Vietnam from 1966-1967. ${ }^{11}$ When Rabe returned, he spent roughly six months processing the last year before he began to try to put his experiences down in some written form. ${ }^{12}$ He did not first seek out theatre as a medium, viewing it as too artificially constructed for expressing what he had experienced: "Theater seemed lightweight, all fluff and metaphor, spangle, posture, and glitter crammed into a form as rigid as any machine geared to reproduce the shape of itself endlessly. Theatrical form seemed artificial beyond what was necessary." ${ }^{13}$ In fact, he found it difficult to record his thoughts regarding the war, with a large number of memories each carrying high priority in his mind. ${ }^{14}$

The process of readapting to civilian life when Vietnam veterans returned home relied upon the ability to forget, to move past their wartime self. The inability of many soldiers returning from Vietnam to accomplish what might be considered a simple task results from the neuroses developed by servicemen from their personal experience in Vietnam: "Many traumatized by twentieth century wars speak of their problem as an inability to forget, as an uncomfortable consciousness of being possessed, 'haunted' by a past they cannot put behind them and which continually intrudes into their present lives." 15 Select returning veterans were immobilized due to their faulty modes of repression, which did not allow them to move forward with their civilian lives. The human ability to not know or accept events and experiences is an element of "historical freedom," not enjoyed by these servicemen who are trapped within the period of the Vietnam war, restricting their actions and causing them to rely on their instincts. The memory of traumatic events frames and controls the contemporary responses and thoughts of whoever shoulders the episode, informing his daily life. ${ }^{16}$ Soldiers who witnessed the destruction of pop culture American manhood firsthand during their service struggled to place themselves in such roles when they began to return from war.

Like his character Pavlo Hummel, who seeks to reproduce the image of macho pop culture figures within himself, when he first returned from Vietnam, Rabe had come to view the medium of theatre as hollow, similar to Hummel's heroes. Having been selected as a medic during Vietnam, Rabe confronted first hand the trappings of traditional male gender roles within the culture of the Army: "The indispensable masculine qualities of the combat soldier have altered little over the long run of modern history: personal courage, the willingness to sacrifice for comrades, the fear of shame or dishonor." 17 In his assigned role as an Army medic, due to the "after-battle" nature of the work, Rabe faced difficulty in fulfilling the requirements for courage and sacrifice. Instead it is evident through Pavlo's fictional experiences, based loosely on Rabe, that Rabe instead developed shame for the secondary nature of his work.

Having served during escalation of the conflict, Rabe returned to a still-

Iowa Historical Review 


\section{Zane Scott-Tunkin}

mobilized civilian society that, due to its wartime mobilization, relied on aggressive militaristic definitions of masculinity, which Rabe could not fulfill due to not having experienced combat on the front lines. The aggressive understanding of masculinity at the time explains why Rabe experienced difficulty returning as noncombat personnel: "Wartime masculinities at home and at the front are governed by... danger and loss. The emotions they provoke generally keep combat masculinities in the foreground and other gendered responses, including noncombat military masculinities, in subordinate positions." ${ }^{18}$ Eventually he came to realize his experiences during the war when placed on a stage as an apt way to communicate the shortcomings of the societal roles American men sought to fill.

Basic Training expands on Rabe's personal experience when Hummel, like Rabe, is assigned to be a medic after completing basic training. Pavlo is colored and influenced by Rabe's firsthand knowledge of the rigidity in the military structure. After a brief stint in the infirmary, Hummel finds it effeminate and demeaning:

CAPTAIN. Don't you think what you're doing here is important?

You helped out with poor Brisbey, didn't you?

PAVLO. Yes, Sir.

CAPTAIN. That's my point Hummel. There are people alive who would be dead if you hadn't done your job. Those invalids you care for, you feed them when they can't, you help them urinate, defecate, simple personal things they can't do for themselves but would die without. Have you asked any one of them if they think what you are doing is important or not, or if you should be ashamed? ${ }^{19}$

Rabe's own experiences dealing with entrenched male stereotypes as an Army medic manifest themselves in Pavlo's belief that as a medic aiding the sick, injured, and dying, he is not fulfilling his purpose, his image of what a man should be. His understanding of masculinity is based largely on a steady diet from his mother of "soldiers of fortune, and film re-creations of war heroism, frontiersmen and cowboys, or rebellious youth." ${ }^{20}$ Handfed these stoic representations, Pavlo learned manly conduct vicariously through them. After returning to the States, Rabe fought himself to understand and place his stint in Vietnam in relation to such unrealistic figures, which helped inform his "male sex role." ${ }^{21}$ Despite believing theatre to be too rigid and unrealistic, Rabe's commercial success Basic Training eventually landed on Broadway, the national bastion of finically viable theatre. The audience's identification with characters like Pavlo Hummel stand 


\section{The Basic Training of Pavlo Hummel}

as a testament not to the validity of Rabe's young perceptions, but instead to the potential for authentic resonance with an audience sharing an experience that theatre offers. ${ }^{22}$ These same elements drew Rabe, who first sought to write a novel, back to the medium after struggling to quantify his own experiences.

Contrary to a novel, theatre is able to nonverbally translate the author's intended message powerfully to an audience. Rabe may not have seen it at the time, but theatre aptly lends itself to communicating the complex experiences of the individual to the group in a more introductory form than perhaps his planned novel. Through endowing one actor with the experiences of Pavlo, each audience came away with a physical and emotional connection to the character, as evidenced by the reviews Rabe received early on, that lauded his persuasiveness, and his ability to, "sense... what people really say and his obvious feel for the dynamics of character confrontation." 23 Rabe's skill at creating complex yet realistic character dialog and argument helped engage audiences with the performance, while he transported them worlds away to experience Vietnam through a specific set of eyes. The realistic representation of Vietnam onstage captivated audiences, who sat uneasily mesmerized in their seats, "through projecting a bravura and completely convincing picture of army life... The audience is not permitted the comfortable options of a morality play or political tract, and the result is as intensely real an experience of what it is like to go to this war as one could ever hope (or bear) to have." ${ }^{24}$ The audience is enveloped within the most realistic encounter with the Vietnam war that they could hope to achieve, Rabe accomplished what many playwrights had sought to do but had fallen short of, eliminate the white noise that surrounded Vietnam and let it speak for itself. In the troubled aftermath of Vietnam, Rabe represented hope for the future, leading one critic to remark, "Vietnam seems to have yielded us up a playwright, if little else to build a dream on." 25 What could be described as the positive legacy of Vietnam formed around those deemed capable of authentically representing and communicating the experiences of America's soldiers.

Having served in Vietnam, Rabe sought to interpret and explain the soldier's experience in Vietnam rather than choosing to use his work to bring about a political and military end to the conflict itself. All of this goes along with Rabe's belief that Vietnam cannot be looked at as a single, solitary event but instead part of a greater human narrative. He does not advocate a particular viewpoint through the character of Pavlo Hummel. Instead he reflects, drawing on his own personal experience, as well as being influenced by those he served with, of how such a single, confusing, and transformative event as war affects and changes an individual. The tale of the fall of Pavlo Hummel forces an audience to deal with more complex issues than simply "for" or "against." The serviceman is treated as an individual, rather than standing for a particular political ideology. Rabe himself disputes the grouping of any of his plays into such constricting categories as "Antiwar":

In my estimation, an "antiwar" play is one that expects,

Iowa Historical Review 


\section{Zane Scott-Tunkin}

by the very fabric of its executed conception, to have political effect. I anticipated no such consequences from my plays, nor did I conceive them in the hope that they would have such consequences... It seems presumptuous and pointless to call them "antiwar" plays... I believe that to think a play can have immediate, large-scale political effect is to overestimate vastly the power that plays have. In addition, if there is (as I deeply hope there is) more content in these plays than the thin line of political tract. $^{26}$

One enters dangerous territory when trying to simplify the response in the American dramatic community to such a complex historical event as the Vietnam War into rigid categories of "Antiwar Plays" or "Vietnam Protest Theatre." While at first glance such categories appear useful and rational in attempts to qualify a large volume of dramatic work, in the end, placing such binaries on something as rich and varied as the multitude of dramatic works coming out of the Vietnam conflict allows one to begin to see how useless such labels really are. While striving for order, Rabe's work can easily and quickly get lumped together with a hodge-podge of experimental and radical groups including the living theatre or the San Francisco Mime Troupe, which sought through their work an effect on the escalating skirmishes and the increasing involvement of United States troops in Vietnam.

The Basic Training of Pavlo Hummel was not performed commercially until 1971 at the Public Theatre as part of the fresh interest in Vietnam on a large scale in traditional American theatres, representing the groundswell that began in 1971 among such theatres, according to Asahina in Levitating the Pentagon. ${ }^{27}$ The late date of the play's original performance chronologically falls short of the many branches of protest theatre, such as the experimental and radical theatre, or "guerilla theatre," and others discussed earlier, that date back as far as 1951 (the living theatre). While Rabe's work often presents Vietnam graphically and in an extremely personal and emotive style, thereby often earning him a place in the broad category of "protest theatre," the traditional structure of his plays, the audience they brought in, and their overall commercial success quickly remove him from the category.

Rabe does not seek out such a tangible goal about Vietnam in his volume of work, partly because he believes that theatre does not have the power to affect the physical realities of the war on the ground. Instead he has written his plays mainly as a cathartic response to his own experiences serving in the conflict: "I have written them to diagnose, as best I can, certain phenomena that went on in and around me... Family, marriage, youth, and crime are all viewed as phenomena permanently a part of the eternal human pageant. I believe war to be an equally 


\section{The Basic Training of Pavlo Hummel}

permanent part of that pageant." 28

Gender weaves itself into any of the phenomenon listed above, coloring how people act and compelling characters to fulfill rigid, impractical, and unattainable ideas of manhood. Nowhere is there as clear a distinction between the sexes as when Sergeant Tower demonstrates how to use a bayonet, clearly associating the female gender with failure and shame, and the male gender with aggression and violence.

SGT. TOWER. What is the spirit of the bayonet?

THE MEN. To kill!

SGT. TOWER. You sound like pussies. You sound like slits.

\section{THE MEN. TO KILL!}

SGT. TOWER. You sound like pussies.

\section{THE MEN. TO KILL! ${ }^{29}$}

The bayonet can be considered a phallic object and the act of shoving it in an enemy akin to sex and a denial of the enemy's masculinity. If the men in basic training cannot control a bayonet, then according to Sergeant Tower, they have assumed the role of a woman. By taking away each soldier's individual identity and transforming the characters into a character of "THE MEN," Rabe's point is even more evident. If Pavlo is a man, he is either with "THE MEN" or he is nothing. This is the distilled version of the idolized manhood that Pavlo enlisted in the Army hoping to find; here it is, laid out bare in the form of dramatic irony. The audience can see the inherent flaws in the black and white choice, but Pavlo must join with the men or abandon his quest for gender realization. In reality, if Pavlo does not join in with "THE MEN" he is no less of a man than if he would become skilled at using a bayonet, but the choice he makes is to either include himself in the demonstration or not. He is presented with no in-between. In this one instant, Pavlo is either a man or he is not.

The Basic Training of Pavlo Hummel presents the process of Pavlo's integration into a new dominant culture, whether military or civilian, upon his return to the States, as one such phenomenon. Pavlo's sour relationship with his mother acts as the catalyst for his enlistment. Because of an argument with her, he voluntarily enlists in the Army during Vietnam, believing that he must prove something to his mother and that the army will confirm for him the fantasy of manhood that Pavlo has been raised on. 


\section{Zane Scott-Tunkin}

PAVLO. And I was wondering also, Sergeant Tower, and wanted to ask you -- when I was leaving home, my mother wanted to come along to the train station, but I lied to her about the time. She would have wanted to hug me right in front of everybody. She would have waved a handkerchief at the train. It would have been awful.

(Sgt. Tower turns; now he is leaving.)

She would have stood there waving. Was I wrong? $?^{30}$

Pavlo believes that he has done the manly thing by not allowing his mother to say goodbye to him at the train station in front of all the other men, but he finds himself questioning whether or not he has done the right thing in the new culture of the military and seeks reassurance from his direct male authority figure, Sergeant Tower.

He seeks Sergeant Tower out as a father figure because of the absence of his father in his life; he had no fallible male role model from which to learn that even those he looks up to are capable of mistakes. Instead, he was raised by his mother on a steady diet of male television and movie stars, who were always presented as unable to do the wrong thing and instill in Pavlo a rigid code of manhood.

PAVLO. Who... was... my father? Where is he?

MRS. HUMMEL. You know that.

PAVLO. No, where is he now? What did he look like?

$\cdots$

MRS. HUMMEL. You had many fathers, many men, movie men, filmdom's great-all of them, those grand old men of yesteryear, they were your father. The Fighting Seventy-sixth, do you remember, oh, I remember, little Jimmy, what a tough little mite he was, and how he leaped upon that grenade, did you see, my God what a glory, what a glorious thing with his little tin hat. ${ }^{31}$ 


\section{The Basic Training of Pavlo Hummel}

In the previous two excerpts, Rabe includes many facets of the "human pageant." Striking out on one's own, gender identity in America, a son's relationship to his mother, and the role of mass media are all touched upon. Rabe utilizes Vietnam as a vessel to bring under scrutiny the code of conduct for men in American society, the Army and how the existing code handicaps Pavlo's search for a father figure and his interactions with women. Contrary to using his drama for the sole purpose of making a statement about the Vietnam War, Vietnam is merely the vehicle with many stops within the American psyche and living room along the way.

Although Rabe is grouped among such radical groups as the San Francisco Mime Troupe and those practicing documentary theatre, Rabe's dramas are relatively safe. In content, all of his plays except for The Basic Training of Pavlo Hummel do not take place in Vietnam, but instead are set in the United States. In performance, one buys a ticket for a certain place and time; the audience is passive and not involved in the action on stage. By the time his first play was produced commercially in 1971, he found a large receptive audience that would carry him to Broadway, evidence that the American audience gravitated to his work, especially Basic Training. ${ }^{32}$ Men were seeing elements of themselves in Pavlo -- their military or school experience, the mothers sitting next to them, and the expectations placed upon them every day, either directly or subtly.

Ardell, Pavlo's guardian angel, acts as the audience's guide to the gender confinement Pavlo ties himself into, one that hinders his range of actions. Ardell begins to point out the shortcomings of the ideal man that Pavlo wants to become, the unattainable goal, which eventually kills him. One of the male cultural mantras embedded in Pavlo's mind is the necessity of revenge. If anyone messes with Pavlo, he believes it is his masculine responsibility to defend his manhood. He has learned that by escalating the mutual hostility and getting the person back, this is an adequate defense.

ARDELL. Like it's gonna make a difference in the world, man, what you do; and s o m e th i n' made bad's gonna be all right with this one more you're gonna kill. Poor ole Ryan gets dinged round about Tay Ninh, so two weeks later in Phu Loi you blow away this goddamn farmer.... ${ }^{33}$

Ardell represents Pavlo's pragmatic voice, the small voice inside for whom an eye for an eye is not an effective code of ethics. Ardell calls out Pavlo on his archaic and faulty assumptions on how a man should behave, showing him that a never ending cycle of his code of manhood would end up getting him and many others killed. Ardell approaches Pavlo's twisted dogma with a principle he believes someone like Pavlo can understand: self-preservation. Ardell's words fall on deaf ears; it is Pavlo's masculine code of conduct that ultimately is his undoing. 


\section{Zane Scott-Tunkin}

Ironically, Pavlo's pop culture model of manhood results in his death over an argument about a whore. Pavlo is negotiating with a prostitute in Vietnam when a sergeant who outranks him enters the same bar; he is subsequently outranked, which sends him into a fury. They argue about who has rights to the prostitute when Pavlo, who will not take "no" for an answer, attacks the sergeant who, in a twist of fate, seeks revenge.

PAVLO. Shut up? (His hand is twisting her hair) I don't know who you think this bitch is, Sarge, but I'm gonna fuck her whoever she is... You don't like it, you best come in, pull me off.

Pavlo kicks him squarely in the groin. He yells, falls.

PAVLO. Did I do it to him, Ardell? The triple Hummel? Got to be big and bad.

$\cdots$

(Sgt. Wall, there in the corner, beginning to move is pulling pin on a grenade.)

(Pavlo drops to his knees, seizing the grenade... The grenade is in his hands in his lap. $)^{34}$

The grenade explodes in his groin, symbolically invalidating in an instant what he has believed all his life. He had striven to fulfill the example left by the actors that portrayed his father. He had failed to protect his manhood. Within the rigid cultural constructs of gender that Pavlo adheres to, he was accomplishing this by securing his first chance with a prostitute. To faithfully "protect his manhood," Pavlo would be forced to choose to reject the simple one-dimensional molds that the iconic men of his childhood were always cast in and embrace his own complexities, rather than fulfilling the static image of his gender. War acts as the perfect method within which to bring out the trappings of harmful, inflexible gender roles. In war, everything becomes more black and white; the individual is stripped of his identity in order to form the successful collective and is full of meaningless clichés such as "turning boys into men."

Rabe's message was clear. The saga of Pavlo Hummel was not about Vietnam, but how the society of the United States had suppressed the aptitude and 
opportunities of its male gender. Plays and dramas, including The Basic Training of Pavlo Hummel, do not and cannot enact large-scale political change, even with astounding success; however, such plays can cause a reaction in the audience. By seeing himself or herself in Pavlo, Mrs. Hummel, or Sergeant Tower, each person begins to realize the rigidity of their actions and how the culture at large has aided in placing them into a box. Hopefully they break out, having seen played out in front of them the extreme and possibly twisted but believable lineage of their actions. Manhood is not an "either/or" entity; instead, an infinitely definable concept has become trapped by motionless icons of masculinity in America's widely distributed popular culture.

This essay was written for Professor Douglas Baynton's Colloquium for History Majors (American) in the fall of 2006. I am in debt to Professor Baynton for allowing students to formulate their own paper topics, in turn forcing us to become deeply personally attached to our work. Art Borreca, head of the Iowa Playwrights Workshop, was also an instrumental compass in the initial hunt for sources.

\section{Endnotes}

1 David Rabe, The Basic Training of Pavlo Hummel and Sticks and Bones (New York: The Viking Press, 1969).

2 Ibid., 7-109.

3 Lucas Carpenter, “'It Don't Mean Nothin': Vietnam War Fiction and Postmodernism," College Literature 30, no.2 (2003), <http://muse.jhu.edu/journals/college_literature/v030/30.2carpenter. html $>$ (26 October 2006).

4 J.W. Fenn, Levitating the Pentagon: Evolutions in the American Theatre of the Vietnam War Era. (Newark: University of Delaware Press, 1992).

5 Ibid., 24-5.

6 The term "guerilla theatre" has been used to describe the members of the radical theatre who came to see themselves as outside agitators, developing a method of taking their performances straight to the audience instead of relying on the audiences' attendance. Born out of the economic realization that theatre space was considerably expensive and tended to place a substantial drain on a group's monetary resources, as well as the fact that their subject matter would not appeal to the conservative member of society, the traditional audience member. The need to leave traditional spaces behind was also built upon their ideology that rejected the terms of the establishment and regarded the traditional audience member as a supporter of the failed conservative status quo. Afraid of "selling out," members constantly searched for a more authentic and free process; see Ibid., 50-1.

7 Ibid., 50-64.

8 Ibid., 63.

9 Mainstream American theatre served as an escape for a public inundated with news reports, including pictures and video that constantly reminded them of the war.

10 Ibid., 87.

11 Nora Atler, Vietnam Protest Theatre: The Television War on Stage (Bloomington: Indiana University Press, 1996), 132.

12 Rabe, The Basic Training of Pavlo Hummel and Sticks and Bones, xii.

13 Ibid., xiii

14 Ibid.

Iowa Historical Review 


\section{Zane Scott-Tunkin}

15 Eric Leed, "Fateful Memories: Industrialized War and Traumatic Neuroses," Journal of Contemporary History 35, no. 1 (2000) <http://links.jstor.org/sici?sici=0022-0094\%28200001\%2 935\%A1\%3C85\%3AFMIWAT\%3E.0.CO\%3B2-J> (3 May 2007).

16 Ibid.

17 Robert A. Nye, "Review Essay: Western Masculinities in War and Peace," The American Historical Review 112, no. 2 (2007), <http://www.historycooperative.org/journals/ahr/112.2/nye. html> (24 April 2007).

18 Ibid.

19 Rabe, The Basic Training of Pavlo Hummel and Sticks and Bones, 90.

20 Robert A. Nye, "Review Essay: Western Masculinities in War and Peace," The American Historical Review 112, no. 2 (2007), <http://www.historycooperative.org/journals/ahr/112.2/nye. html> (24 April 2007).

21 R.W. Connell, "The Big Picture: Masculinities in Recent World History," Theory and Society 22, no. 5 (1993), <http://links.jstor.org/sici?sici=0304-2421\%28199310\%2922\%3A5\%3C597\%3A TBPMIR\%3E2.0.CO\%3B2-A> (24 April 2007).

22 David Rabe, The Basic Training of Pavlo Hummel and Sticks and Bones (New York: The Viking Press, 1969), xix-xx.

23 Clive Barnes, “Theater: ‘Training of Pavlo Hummel,” The New York Times, 21 May 1971, p. 25. $<$ http://proquest.umi.com> (2 May 2007).

24 Peter Schjeldahl, "Pursuing a 'Bogus Manhood," The New York Times, 11 July 197, D1. <http:// proquest.umi.com> (2 May 2007).

25 Robert Berkvist, "If you kill somebody...," The New York Times, 12 December 1971, D3. <http: proquest.umi.com> (2 May 2007).

26 Rabe, The Basic Training of Pavlo Hummel and Sticks and Bones, xxv.

27 Ibid., xii-xix.

28 Ibid., xxv.

29 Ibid., 44.

30 Ibid., 29.

31 Ibid., 74-5.

32 Ibid., xix-xx.

33 Ibid., 99.

34 Ibid., 105-06.

Zane Scott-Tunkin is in his second year at the University of Iowa, majoring in history and social studies education with an English minor. After his graduation in the spring of 2009, he plans to become a high school history teacher or pursue graduate studies in history, library science, or social studies education. Zane is interested in American social and cultural history relating to architecture, gender, media, and the performing arts. 